\title{
Postdictions of 20-year predictions about the state of computer technology in psychology (and one or two other matters)
}

\author{
GEOFFREY R. LOFTUS \\ University of Washington, Seattle, Washington
}

\begin{abstract}
I make three general points. First, I argue that the conjunction of two important characteristics prevents computer technology from becoming tedious and boring. Second, I discuss the fate of several "postdictions" of what we would have predicted about 1990 computer technology 20 years ago. Third, I discuss the degree to which computer technology drives research rather than the other way around.
\end{abstract}

In this brief paper, I should like to consider three points. First, I shall comment on a remark made by Don Tepas previously (Tepas, 1991). Second, I want to discuss what my colleague, Colin MacLeod has termed the "postdiction of predictions" (personal communication). By this I mean mentally transporting ourselves back, 20 years, to the time at which this society was founded, and trying to decide what we then would have predicted about the state of computer technology 20 years hence (i.e., right now). Finally, one of these postdictions-having to do with the degree to which technology drives research, rather than the other way around-seems interesting enough to warrant being a point by itself. So a discussion of that issue will come third.

\section{Computer Technology as an Exception \\ to the "Dreariness Trap"}

Earlier in this symposium, Don Tepas made the provocative point that all technologies undergo the dreary cycle of being at first exciting, but then repetitious and boringand he stated that computer technology is not exempt from this rule (Tepas, 1991). Don illustrated this point by noting that the first computer program you write is a great deal of fun, but that after that, the process of writing similar computer programs starts to degenerate into tedium. This process has analogues in many other activities. For example, when we were younger, our first experiences of driving cars were great fun. As time went by, however, driving became routine, and getting behind the wheel degenerated into an experience of boredom and irritation rather than one of excitement and joy.

I find that I disagree with this position. I believe that computer technology incorporates a conjunction of two properties that exempts it from this general rule. These are hierarchical organization and ease of use.

I thank Colin MacLeod for his invaluable help in preparing this talk during the course of a splendid trip from New Orleans to Mobile and back. The writing up of this work was supported by an NIMH grant to G. Loftus. Correspondence should be addressed to Geoffrey R. Loftus, Department of Psychology, University of Washington, Seattle, WA 98195.
Hierarchical organization. Computer programming (and computer technology more generally) is heavily hierarchical. It is true that if you write a program at the same hierarchical level over and over again, it can get tedious. However, if you write routines that you (1) can use as modules so that you do not have to write them again and (2) can combine these modules into higher level routines, then you are continually doing different things rather than just doing the same thing over and over. Most presently used programming languages (e.g., Pascal and C), as well as many emerging applications (e.g., Mathematica), lend themselves to this process very nicely.

Ease of use. It could be argued that any technology is, in principle, hierarchical. Electronics technology, for example, involves little wires and things getting combined into resistors and transistors, which get combined into chips, which get combined into almost anything. However, most technologies (electronics included) require that one acquire specialized and somewhat difficult manual skills in order to create new products at ever-higher hierarchical levels. Such skills are not, however, necessary if you want to use computer technology; you merely need to be able to type and to guide a mouse. Any bright 10year-old possesses the skills to become a computer programmer capable of building arbitrarily complex programs; however, it would take the same 10-year-old a lot of work to develop the manual skills necessary to build, say, a radio.

\section{Postdictions of Predictions}

In preparation for this symposium, my colleague Colin MacLeod and I invented a game called "postdiction of 20-year-old predictions." This game involves (1) trying to think back 20 years and reconstruct what our general view of computer technology was back then, (2) trying to imagine what we would have predicted the role of computers in psychology to be 20 years hence (i.e., right now), and (3) trying to figure out why there are discrepancies between these postdictions on the one hand and actual present technology on the other. 
This is an exercise that is useful, and fun, for anyone to carry out. In what follows, I will briefly discuss three of our postdictions. Then I will discuss a fourth in somewhat more detail.

Raw power. Not surprisingly, the first postdiction (which actually subsumes most of the others) is that we never would have come close to predicting how powerful (fast and memory-rich) present computer systems would be. This is, in large part, a consequence of making linear predictions about an exponentially expanding phenomenon.

Pervasiveness. Second, we would have predicted that the computer would still be primarily a laboratory instrument, used almost exclusively for data collection (and maybe, to a limited extent, data analysis). Never would we have dreamed that, for most of us, word processing and the use of electronic mail would far outstrip lab work as a source of scientist/computer interaction (cf. Church, 1983, for a state-of-the-art description of psychologist/ computer intertwinement 7 years ago, and note how even then we were in the dark ages relative to where we are now). This failure of prediction stems from our utter lack of vision about the degree to which computers would become commercialized-and the degree to which commercialization would lead to the concomitant explosion of multipurpose applications, available at our neighborhood software outlet (or, indeed, our neighborhood bookstore or convenience store).

Allocation of blame. Twenty years ago, computers were mysterious. Both psychologists who used them in the laboratory and real people who used them in the real world blamed computers for any technological snafu. This was psychologically convenient in many respects; the computer was an inscrutable demon into whose lap we could dump the geneses of our problems, thereby avoiding the necessity of blaming ourselves. Naturally, we assumed 20 years ago that this would always be true.

Now, however, in the laboratory, in the office, and in real life, computers are part of the environment. When something goes wrong, we are more inclined to blame ourselves. This may represent the loss of a defense mechanism, but at the same time, we feel more in control-we feel that when there is a technological problem (the laboratory computer is not opening the projector shutters, or the analysis program is producing random numbers), we know where to begin to solve it. Or at least we know whom to ask.

\section{The Horse and the Cart}

One more postdiction seemed sufficiently interesting to deserve its own section. This involves the degree to which the research issues that we tackle are determined by available computer technology, rather than the other way around.

In my presidential address to this society, I discussed this issue with respect to computer simulation (Loftus, 1985). I made the point then that, to an alarming degree, theory in the social sciences is driven by the capability of constructing large computer simulation models. This capability, I argued, removed the incentive to strive for simple theories describing simple situations-a strategy that has served science well for centuries. To illustrate this point, I assembled a fantasy in which Johannes Kepler possessed a computer-resulting, ultimately, in a solar system described by an enormously complicated epicyclicalsystem rather than by three simple laws.

To some degree, I feel, this same trend is occurring in experimentation as well as in theory construction. We get a new computer system or a new CRT, or a new timer or a new plotter, and it immediately suggests to us a brand-new research area. Or, just being able to use a computer to collect data at all provides the irresistible temptation to make our experiments more complex than they otherwise would have been. (Why not add an extra independent variable, after all, if we can collect the data four times as fast as we used to be able to do?) This is quite different from what it was 20 years ago, when we selected a research topic on the basis of its "intrinsic importance" (whatever that may be) and then, if we could, tailored our existing computer systems to deal with that topic.

I have discovered, however, that I am not nearly as alarmed by this trend as I was about the trend toward theory as computer simulation. The choice of a specific topic area in any research endeavor is, I believe, more intrinsically arbitrary and idiosyncratic than is the choice of whether to construct simple theories of simple phenomena or complex theories of complex phenomena. In other words, research topics are always generated by enigmatic means; such means may consist just as well of the availability of suitable experimental technology as of anything else. From an objective stance, there may be the liability of having more complex designs that we have to try to understand, which is bad (in my opinion, anyway); but there is also the asset of having the capability of a lot more experimental control, which is good.

\section{Et Alia}

1 want to conclude this essay by going back to Don Tepas's (1991) remarks about technological drudgery. In 1970 , I spent a lot of time preparing experiments by picking my way through the Rand book of random numbers. In 1990 , I spent a lot of time preparing experiments by writing Pascal programs. I am much happier now than I was then.

\section{REFERENCES}

СнURCH, R. M. (1983). The influence of computers on psychological research: A case study. Behavior Research Methods \& Instrumentation, 15, 117-126.

LoFTUS, G. R. (1985). Johannes Kepler's computer simulation of the universe: Some remarks about theory in psychology. Behavior Research Methods, Instruments, \& Computers, 17, 149-156.

TEPAs, D. I. (1991). Computers, psychology, and work: Does the past predict a troubled future for this union? Behavior Research Methods, Instruments, \& Computers, 23, 101-105. 